\title{
LABs Responsible for Enhancing Antibiotic Susceptibility Pattern and Gene Transference
}

\author{
Maham Ghouri*, Naheed Afshan, Sumaira Javed and Sayyada Ghufrana Nadeem \\ Department of Microbiology, Jinnah University for Women, Karachi, Pakistan.
}

\begin{abstract}
Probiotics are gram positive organisms considered beneficial for combating with various pathogens. Most of them are antibiotic resistant, giving an idea that they may be carrier of r-plasmids. Our aim of the study was to determine the proportion of LABs that associate with r-gene transference as well as in boosting up antibiotic susceptibility range. For that we isolated probiotic cultures of Streptococcus, Lactobacillus, and Leuconostoc from milk sample, and checked the susceptibility pattern of isolated probiotics and pathogens (test organisms) against carbepenem. Results showed all LABs are resistant, while most of the pure test organisms were sensitive, after that these pathogens were treated with Labs coated disc that was prepared by the Kirby Bauer method. These LAB treated organisms were again checked with carbepenem to check the susceptibility pattern, this whole protocol was carried out on Muller Hinton Agar (MHA) plate. According to our results test organisms treated with Streptococcus and Lactobacillus species occurred with a $20 \%$ and $1 \%$ of resistivity, while organisms treated with Leuconostoc species enhanced the sensitivity $66 \%$ and streptococcus $1 \%$, whereas Lactobacillus did not show any change in antibiotic spectrum.
\end{abstract}

Keywords: Probiotics, kirby bauer method, carbepenem, susceptibility pattern.

doi.org/10.21089/njhs.11.0017

\section{INTRODUCTION}

Probiotics group of gram positive live as a single or colonized form; tend to play essential role in improving men's immunity by maintaining the normal flora. These organisms produce secondary metabolites that carry antimicrobial activity against many of the pathogenic organisms [1], use in food and in aquaculture [2]. These gram positive bacteria are categorized as LAB [1], they are usually used as starter culture in production of dairy items. LABs are categorized in different groups [3]. These can be identified on the basis of $\mathrm{pH}$ motility, microscopy, catalase and oxidase production, $\mathrm{NaCl}$ and bile tolerance [15, 4, 29]. These organisms play role in reducing the lactose intolerance and cholesterol level, antitumor activity and activation of immune system [5]. The taxonomic tool for their identification is fructose-6-phosphate phosphoketolase (F6PPK) [5, 6]. The identification of these can be possible at molecular level by PCR. The backbone of streptococcus bacteria is joined together by ether linkages which separates it from other bacterial species, virulent streptococcus species due to absence of surface proteins (lipoproteins) [7]. Exopolysaccharide genes eps E, eps G, eps I play an important role in the production of fat reducing cheddar cheese and other dairy products $[7,8]$. They boost up human

\footnotetext{
*Address correspondence to this author at the Department of Microbiology, Jinnah University for Women, Karachi, Pakistan,

E-mail: mahamghouri95@hotmail.com
}

immunity, present as intestinal flora (increase digestion) [10, 14] used in replacement of chemotherapy [11] and also in the treatment of Antibiotic associated diarrhea [12, 13-15]. Now days, it has gained popularity among researchers because in $\mathrm{S}$. thermophillus, the genome is shorter than most, $1.8 \mathrm{Mb}$ [9].

\section{PROBIOTICS AND GENE - ACQUISI-TION}

Today, probiotics have gained a lot of consideration and can be used as a standby for antibiotic growth promoter. [16, 17]. The difference in dosage is due to variation in persons age, sex and environmental factors $[18,19]$. These are beneficial against intestinal pathogens. Most use is lactobacillus and streptococcus [25]. In efficient case of diarrhea [20, 25, 28]. Probiotics blocks the receptor sites antagonistically [21]. Firstly, viral replication is inhibited by the limiting nutrients to overcome diarrhea [22]. Secondly, they also produce antibodies, releasing cytokines and initiate cell mediated immunity that boost up the immunity [22]. Third mechanism is they inhibit motility of these pathogens by releasing cytokines and nitric oxide [23]. Manner A [24], shows in his in vitro study that lactobacilli produces such substances that have the capability to inhibit virions [24].

\section{Probiotics in Developing Resistance}

Resistance to antibiotic is the most controversial topic now a day. Most of the pathogen gets resistance genes. Mammalian Intestinal flora provides a most favorable environment for 
gene transference between many bacterial species. No association of gene transfer identifies among dissimilar genus (Fungi-Bactria), fungi itself are able to produce medicinal components as a secondary metabolite [26].

\section{Phylogeny of Antibiotic Resistance Genes}

In past horizontal gene transfer is difficult experimentally in taxonomically different group of bacteria. It totally depends on the environmental conditions. The phylogenetic approach was applied to analyze the metamorphic record of antibiotic resistance genes, encoding ribosomal protection proteins which play important role as substitute of elongation factors and confer resistance to tetracyclines [27].

\section{MATERIALS AND METHODS}

\section{Isolation of Probiotic Organisms}

In this study isolation of Probiotics was done by camel milk. Milk sample was swabbed on De Man, Rogosa and Sharpe (MRS) agar prepared medium purchased from Merk. Plate was incubated at $37^{\circ} \mathrm{C}$ for $48-72$ hours to analyze the colony morphology [21, 22]. Gram staining was performed for microscopic analysis. It was sub cultured further to get pure colonies by inoculating single colony on MRS agar for lactobacillus spp, MRS supplemented with L-cystien $0.05 \%$ for the streptococcus (fat lowering bacteria) [23, 24] incubate at $37^{\circ} \mathrm{C}$ for 24 and 48 hours respectively, colonies were inoculated on Heart Infusion agar supplemented with 5\% glucose (HIAG) and Heart Infusion Agar supplemented with $5 \%$ Sucrose, $0.5 \%$ Glucose, and $0.02 \%$ Sodium azide (HIAS) colonies obtained from HIAS were inoculated on Mayeux Sandine Elliker agar (MSE) prepared by adding (Tryptone 10g/l, Gelatine 2.5g/l, Yeast extract 5g/l, Sucrose $100 \mathrm{~g} / \mathrm{l}$, Glucose 5g/1, Sodium Azide 75mg/l, Sodium citrate $1 \mathrm{~g} / \mathrm{l}$, Agar $15 \mathrm{~g} / \mathrm{l}$ ) which is elective medium for Leuconostoc species and incubated at $30^{\circ} \mathrm{C}$ for 3 days. Spot Tests of all the LAB were determined on the basis of motility, catalase, and oxidase by picking up colonies from their respective medium plates. Motility of isolated cultures was determined by cavity slide technique, leuconostoc was confirmed by growing in $6.9 \% \mathrm{NaCl}$. Further, it was confirmed by microscopy. We collected various pathogenic organisms from different diagnostic laboratories like Shigella Brunetti, Acinetobacter baumannii, Klebsiella pneumoniae, Pseudomonas aeruginosa, Staphylococcus aureus, Proteus vulgaris, Escherichia coli, Listeria monocytogenes, Micrococcus luteus and Salmonella. These were treated with a synthetic drug, Imipenem, (belong to the group of Carbepenem drug, this was used because most organisms are resistant to this drug). Probiotics were also treated with Imipenem to check the presence of resistivity genes, these were compared with the results of Lab treated organisms and Bacteriocin treated organisms. Bacteriocin was obtained by isolating the organism from respective mediums and inoculated in MRS broth (for lactobacillus species), MRS broth supplemented with L-cysteine (Streptococcus thermophillus), MRS with $6.5 \% \mathrm{NaCl}$ (for Leuconostoc). All the broth cultures were further tested for antibacterial activity by agar well disk diffusion method, in which LAB grows them and inhibits test organisms. All tubes were incubated at $37^{\circ} \mathrm{C}$ for $48-72$ hours while Leuconostoc at $30^{\circ} \mathrm{C}$ for 72 hours (as these organisms produce bacteriocin in late log phase). All the tubes was centrifuged at 6000 RPM for 20 minutes, transparent supernatant were separated out by the help of sterile syringe passing it through the $0.2 \mathrm{NM}$ filter assembly to avoid any of the bacterial contamination to collect in screw caped test tube and refrigerate at $-20^{\circ} \mathrm{C}$. Sensitivity of human pathogen was checked out by following disk diffusion method as given by Kirby-Bauer Method on nutrient and MHA agar. Zones were considerd sensitive if break-point is greater than $8 \mathrm{~mm}$. All the organisms were checked for gene acquisition, after treating with bacteriocin, if there was any phylogenetic change observed. For this we took LAB treated test organisms and pure isolates; checked susceptibility pattern against synthetic drug that is imipenem by the Kirby-Bauer method. Observed susceptibility patterns of both LAB treated and pure isolates. This method is performed for all LABs that are isolated from the Raw Dromedary Camels Milk. If there is a decrease in sensitivity pattern as compared to the standard result of Imipenem this indicates Resistivity gene transference is accomplished [26, 27, 29].

\section{DISCUSSION}

The study was carried out in the Microbiology department of Jinnah University for Women, Pakistan. Different Probiotics had been isolated from the milk sample. All isolates were purified by growing in their respective supplemented medium and spot tests. Lactobacillus spp, Streptococcus spp, Leuconostoc, gram positive long and short rods of bacillus, cocci in chains, cocco bacillary identified under microscope. While all are oxidase and spores Negative, non motile except for leuconostoc, catalase negative except for Lactobacillus that is considered as pseudo positive [24, 26, 27]. Bacteriocin had been extracted from the late log phase stage. Antibiotics enhancing effects and gene acquisition with probiotics were observed by using synthetic drugs on pure pathogenic isolates and on LAB treated pathogenic isolates. Table 1 showes the susceptibility patterns of pure isolates Shigella burnetti, Acinitobacter baumannii, Klebsiella pneumoniae, Staphylococcus au-reus, Proteus vulgaris, against Imipenem, which was $25 \mathrm{~mm}, 25 \mathrm{~mm}, 17 \mathrm{~mm}, 24 \mathrm{~mm}$, $28 \mathrm{~mm}$ and $22 \mathrm{~mm}$ respectively, while LAB treated isolates were Eschereshia coli, Acinitobacter baumannii, Listeria monocytogenes, Pseudomonas aureginosa, Staphylococcus. aureus, Micrococcus leutes, and Klebsiella pnumoniae, with 


\section{RESULTS:}

Table 1a. Microscopic Analysis.

\begin{tabular}{|c|c|c|c|}
\hline Isolated Organisms & Media & Microscopic Characteristics & Colony Morphology \\
\hline $\begin{array}{l}\text { Mix Culture from } \\
\text { dromedary milk. }\end{array}$ & MRS & $\begin{array}{l}\text { Gram positive, rods, cocci. } \\
\text { Cocobacilus, scattered. }\end{array}$ & \\
\hline Lactobacillus spp & MRS & $\begin{array}{l}\text { Gram positive, Long and short } \\
\text { rods of bacillus }\end{array}$ & \\
\hline $\begin{array}{l}\text { Streptococcus. } \\
\text { thermophillus }\end{array}$ & MRS + L-Cystien & Cocci in chains & \\
\hline Leuconostoc & $\operatorname{MSE}(6.9 \% \mathrm{NaCl})$ & Coccobacillary & \\
\hline Pediococcus & MRS+ L-cysteine & Cocci in tetrades & \\
\hline Yeast cells & MRS+ L-Cystien & Round to oval scattered cells & \\
\hline
\end{tabular}


Table 1b. Spot Tests for differentiation of LAB.

\begin{tabular}{|c|c|c|c|c|c|}
\hline Isolated Organisms & Catalase & Oxidase & Motility & Spores & Gram Reaction \\
\hline Lactobacillus spp & Negative (pseudo-positive) & Negative & Negative & Negative & Positive Rods \\
\hline Streptococcus. thermophillus & Negative & Negative & Negative & Negative & Positive cocci \\
\hline Leuconostoc & Negative & Negative & Positive & Negative & Positive coccobacillus \\
\hline Pediococcus & Negative & Negative & Negative & Negative & Positive cocci \\
\hline Yeast & - & Negative & Negative & Purple ovoid cells \\
\hline
\end{tabular}

Table 2. Effect of Synthetic drug on Untreated bacterial cultures.

\begin{tabular}{|c|c|c|c|c|}
\hline S. No. & Test Organisms & Media & Drug & Zones \\
\hline $1-$ & Shigella burnetti & MHA & Imipenem & $25 \mathrm{~mm}$ \\
\hline $2-$ & Acinitobacter baumannii & MHA & Imipenem & $25 \mathrm{~mm}$ \\
\hline $3-$ & Klebsiella.pneumoniae & MHA & Imipenem & $17 \mathrm{~mm}$ \\
\hline $4-$ & Pseudomonas.aureginosa & MHA & Imipenem & $24 \mathrm{~mm}$ \\
\hline $5-$ & Staphylococcus.aureus & MHA & Imipenem & $28 \mathrm{~mm}$ \\
\hline $6-$ & Proteus vulgaris & MHA & Imipenem & $22 \mathrm{~mm}$ \\
\hline 7- & Salmonella typhi & MHA & Imipenem & $40 \mathrm{~mm}$ \\
\hline
\end{tabular}

*All isolated Labs were resistant to Imipenem which indicates presence of Resistivity genes.

Table 3. Effects of Synthetic Drug on LAB treated Test organisms.

\begin{tabular}{|c|c|c|c|c|}
\hline S. No. & Test Organisms (LAB Treated) & Media & Drug & Zones \\
\hline $2-$ & Acinitobacter baumannii & MHA & Imipenem & $18 \mathrm{~mm}$ \\
\hline 4- & Pseudomonas aureginosa & MHA & Imipenem & $22 \mathrm{~mm}$ \\
\hline $5-$ & Staphylococcus aureus & MHA & Imipenem & $25 \mathrm{~mm}$ \\
\hline $6-$ & Micrococcus leutes & MHA & Imipenem & $\mathrm{R}$ \\
\hline
\end{tabular}


Table 4. Screening of Bactericin by Comparing With Gene-Acquisition to Check Resistivity Pattern or Sensitivity in Combination with Synthetic Drug.

\begin{tabular}{|c|c|c|c|}
\hline S. No. & Test Organisms (Untreated) & Zone of Prepared Disks of Streptococcus & Media \\
\hline $1-$ & Eschereshia coli & $12 \mathrm{~mm}$ & Nutrient Agar \\
\hline $2-$ & Acinitobacter baumannii & $15 \mathrm{~mm}$ & Nutrient Agar \\
\hline $3-$ & Listeria monocytogenes & Nutrient Agar \\
\hline $4-$ & Pseudomonas aureginosa & $19 \mathrm{~mm}$ (no geen pigment production) & Nutrient Agar \\
\hline $5-$ & Staphylococcus aureus & $16 \mathrm{~mm}$ & Nutrient Agar \\
\hline $6-$ & Micrococcus leutes & $10 \mathrm{~mm}$ & Nutrient Agar \\
\hline $7-$ & Klebsiella pneumoniea & $19 \mathrm{~mm}$ & Nutrient Agar \\
\hline $8-$ & Proteus vulgaris & $20 \mathrm{~mm}$ & Nutrient Agar \\
\hline $9-$ & Shigella burnetti & Nutrient Agar \\
\hline
\end{tabular}

Table 5. Effects of Effect of Imipenem on LAB (Streptococcal) treated pathogens for Gene-Acquisition.

\begin{tabular}{|c|c|c|c|c|}
\hline S. No. & Test Organisms (Treated ) & Media & Drug & Zones \\
\hline $1-$ & Eschereshia coli & MHA & Imipenem & $15 \mathrm{~mm}$ \\
\hline $2-$ & Acinitobacter baumannii & MHA & Imipenem & $20 \mathrm{~mm}$ \\
\hline $3-$ & Listeria monocytogenes & MHA & Imipenem & $18 \mathrm{~mm}($ pigment production) \\
\hline $4-$ & Pseudomonas aureginosa & MHA & Imipenem & $25 \mathrm{~mm}$ \\
\hline $5-$ & Staphylococcus aureus & MHA & Imipenem & $23 \mathrm{~mm}$ \\
\hline $6-$ & Micrococcus leutes & MHA & Imipenem & $29 \mathrm{~mm}$ \\
\hline $7-$ & Klebsiella pneumoniea & MHA & Imipenem & $29 \mathrm{~mm}$ \\
\hline $9-$ & Proteus vulgaris & MHA & Imipenem & $25 \mathrm{~mm}$ \\
\hline
\end{tabular}

Table 6a. Efficiency of extracted bacteriocin from Lactobacillus on untreated bacterial cultures.

\begin{tabular}{|c|c|c|c|}
\hline S. No. & Test Organisms (Untreated) & Media & Zone of Prepared Disks of Lactobacillus \\
\hline $1-$ & Eschereshia coli & MHA & $30 \mathrm{~mm}$ \\
\hline $2-$ & Salmonella typhi & MHA & $\mathrm{R}$ \\
\hline $3-$ & Pseudomonas aureginosa & MHA & $\mathrm{R}$ \\
\hline $4-$ & Shigella burnetti & MHA \\
\hline
\end{tabular}




\begin{tabular}{|c|c|c|c|}
\hline $5-$ & Staphylococcus aureus & MHA & $\mathrm{R}$ \\
\hline $6-$ & Micrococcus leutes & MHA & $\mathrm{R}$ \\
\hline $7-$ & Klebsiella pneumoniea & MHA & $\mathrm{R}$ \\
\hline $8-$ & Proteus vulgaricus & MHA & $\mathrm{R}$ \\
\hline
\end{tabular}

Table 6b. Effect of Imipenem on LAB (Lactobacillus) treated pathogens for Gene-Acquisition.

\begin{tabular}{|c|c|c|c|c|}
\hline S. No. & Test Organisms (Untreated) & Media & Drug & Zones \\
\hline $1-$ & Eschereshia coli & MHA & Imipenem & $\mathrm{R}$ \\
\hline $2-$ & Salmonella typhi & MHA & Imipenem & $\mathrm{R}$ \\
\hline $3-$ & Pseudomonas aureginosa & MHA & Imipenem & $\mathrm{R}$ \\
\hline $4-$ & Shigella burnetti & MHA & Imipenem & $\mathrm{R}$ \\
\hline $5-$ & Staphylococcus aureus & MHA & Imipenem & $\mathrm{R}$ \\
\hline $6-$ & Micrococcus leutes & MHA & Imipenem & $\mathrm{R}$ \\
\hline 7- & Klebsiella pneumoniea & MHA & Imipenem & $\mathrm{R}$ \\
\hline
\end{tabular}

Table 7a. Efficiency of extracted bacteriocin from Leuconostoc on untreated bacterial cultures.

\begin{tabular}{|c|c|c|c|}
\hline S. No. & Test Organisms (Untreated) & Media & Zone of prepared Disks of Leuconostoc \\
\hline $1-$ & Eschereshia coli & Nutrient Agar & $\mathrm{R}$ \\
\hline $2-$ & Acinitobacter baumannii & Nutrient Agar & $\mathrm{R}$ \\
\hline $3-$ & Listeria monocytogenes & Nutrient Agar & $\mathrm{R}$ \\
\hline $4-$ & Psuedomonas aureginosa & Nutrient Agar & $\mathrm{R}$ \\
\hline $5-$ & Staphylococcus.aureus & Nutrient Agar & $15 \mathrm{~mm}$ \\
\hline $6-$ & Micrococcus leutes & Nutrient Agar & $19 \mathrm{~mm}$ \\
\hline $7-$ & Klebsiella.pneumoniae & Nutrient Agar & $\mathrm{R}$ \\
\hline $9-$ & Proteus.vulgaricus & Nutrient Agar & \\
\hline
\end{tabular}

Table 7b. Effect of Imipenem on LAB (Leuconostoc) treated pathogens for Gene-Acquisition.

\begin{tabular}{|c|c|c|c|c|}
\hline S. No. & Test Organisms (Treated) & Drug & Media & Zone \\
\hline $1-$ & Eschereshia.coli & Imipenem & MHA & $32 \mathrm{~mm}$ \\
\hline
\end{tabular}




\begin{tabular}{|c|c|c|c|c|}
\hline $2-$ & Acinitobacter baumannii & Imipenem & MHA & $23 \mathrm{~mm}$ \\
\hline 3- & Listeria.monocytogenes & Imipenem & MHA & $25 \mathrm{~mm}$ \\
\hline 4- & Psuedomonas.aureginosa & Imipenem & MHA & $28 \mathrm{~mm}$ \\
\hline 5- & Staphylococcus.aureus & Imipenem & MHA & $35 \mathrm{~mm}$ \\
\hline $6-$ & Micrococcus leutes & Imipenem & MHA & $30 \mathrm{~mm}$ \\
\hline 7- & Klebsiella.pneumoniae & Imipenem & MHA & $32 \mathrm{~mm}$ \\
\hline 8- & Proteus.vulgaricus & Imipenem & MHA & $29 \mathrm{~mm}$ \\
\hline 9- & Shigella.burnetti & Imipenem & MHA & $27 \mathrm{~mm}$ \\
\hline
\end{tabular}

$19 \mathrm{~mm}, \quad 18 \mathrm{~mm}, 27 \mathrm{~mm}, 22 \mathrm{~mm}, 25 \mathrm{~mm}, \quad \mathrm{R}, \quad 25 \mathrm{~mm}$, respectively. Streptococcus is playing $22 \%$ role in resistance gene transference Major organisms were Acinitobacter baumannii and Pseudomonas aureginosa that showed $1 \%$ enhanced antibiotic susceptibility, Lactobacillus is involving $1 \%$ resistance gene transference. On the other hand Leuconostoc is not involved in gene transference while enhancing the antibiotic susceptibility pattern about $66 \%$. LABs are resistant to many of the antibiotics [30]. This is indication that LAB may be involved in gene transference within the pathogens. [31] Also reported that different Labs like Lactobacillus spp and streptococcus species in GIT are involved in Resistance gene transference [31]. GTF gene, is accountable for the coding of glucosyltransferase (GTF) and has the capability to produce polysaccharides from sucrose, that was obtained by means of transposons from various LAB, e.g. Lactobacillus and Streptococcus come across in fermented food [32]. According to another study [33]. It is revealed that probiotics in combination with synthetic drug are responsible for a better antibacterial activity. It requires small dose to treat a disease with any probiotic formula that is also observed in our results, most of the organisms involved are leunonostoc treated Staphylococcus aureus, Shigella burnetti, Klebsiella pneumonia, Proteus vulgaris, Pseudomonas. Aureginosa

\section{CONCLUSION}

Nowadays, probiotics are gaining importance and are used as a stand by (growth promoter) instead of multiply resistant drug. Probiotics are given with different dosages in accordance with sex, age and environmental factors. It is specially used against intestinal, pathogens and boost up immunity level. Purpose of this study was to determine antibiotic susceptibility pattern and differentiate antibiotic resistence gene transference.

\section{CONFLICT OF INTEREST}

Declared none.

\section{ACKNOWLEDGEMENT}

Fund for study Jinnah University.

\section{REFERENCES}

[1] Yateem, A, MT Balba, T Al-Surrayai, B Al-Mutairi, and R AlDaher. "Isolation of Lactic Acid Bacteria with Probiotic Potential from Camel Milk." Int. J. Dairy Sci., 3, 2008; 4: 194-99.

[2] Khandelwal, Joshi H. and Chaudhary Antagonistic effect of Lactobacilli of Camel Milk against Aeromonas veronii isolated from Pichola lake Mohan lal Sukhadia University, Udaipur-313001, Rajasthan, B.L. Department of Biotechnology, India Res. J. Recent Sci., ISSN 2277-2502. 2015; 4 (ISC-2014), 170-172.

[3] Fatma, C.H. and Benmechernene, Z. Isolation and identification of Leuconostoc mesenteroides producing bacteriocin isolated from Algerian raw camel milk. Afr. J. Microbiol. Res., 2013; 7(23), 2961-2969.

[4] Pyar, Hassan. and Peh, K., Characterization and identification of Lactobacillus acidophilus using biolog rapid identification system. Int. J. Pharm. Pharm. Sci., 2014; 6(1), 189-193.

[5] Eva Vlkova, Jana Markova, And Vojtech Rada, Comparison of four methods for identification of Bifidobacteria to genus level, Czech J. Food Sci., 2002; 20: 171-174.

[6] Miloud hadadji, rabha benama, Noureddine SAIDI, Djamal Eddine HENNI and Mebrouk KIHAL*, 2005, Identification of cultivable Bifidobacterium species isolated from breast-fed infants feces in West-Algeria, Es-senia Oran. Algeria, 3110018 Francesca Stingele.

[7] S. Awad, A.N. Hassan, K. Muthukumarappan, 2005, Application of Exopolysaccharide-Producing Cultures in Reduced-Fat Cheddar Cheese: Composition and Proteolysis. J. Dairy Sci., 88: 4204-4213.

[8] Rao, M.V. and Dutta, S.M. Production of beta-galactosidase from Streptococcus thermophilus grown in whey. Appl. Environ. Microbiol., 1977; 34(2): 185-188.

[9] Wollowski, I., Rechkemmer, G. and Pool-Zobel, B.L., Protective role of probiotics and prebiotics in colon cancer. Amer. J. Clin. Nut., 2001; 73(2): 451s-455s.

[10] Whitford, E.J., Cummins, A.G., Butler, R.N., Prisciandaro, L.D., Fauser, J.K., Yazbeck, R., Lawrence, A., Cheah, K.Y., Wright, T.H., Lymn, K.A. and Howarth, G.S., 2009. Effects of Streptococcus thermophilus TH-4 on intestinal mucositis induced by the chemotherapeutic agent, 5-Fluorouracil (5-FU). Cancer Biol. Ther., 8(6): 505-511. 
[11] Nopchinda, S., Varavithya, W., Phuapradit, P., Sangchai, R., Suthutvoravut, U., Chantraruksa, V. and Haschke, F. Effect of bifidobacterium $\mathrm{Bb} 12$ with or without Streptococcus thermophilus supplemented formula on nutritional status. J. Med. Assoc. Thai.= Chotmaihet Thangphaet, 2002; 85: S1225-31.

[12] Beniwal, R.S., Arena, V.C., Thomas, L., Narla, S., Imperiale, T.F., Chaudhry, R.A. and Ahmad, U.A. A randomized trial of yogurt for prevention of antibiotic-associated diarrhea. Digestive Diseases and Sciences, 2003; 48(10): 2077-2082.

[13] Pierre Bourlioux Professor of microbiology, The intestinal microbial ecosystem still has some surprises for us, Letter N 21, 2005.

[14] K. Khedida,b, M.Faidc, A.Mokhtarib, A. Soulaymanib, A. Zinedined, Characterization of lacticacid bacteria isolated from the one humped camel milk produced in Morocco, Microbiological Research. 164 2009; 81-91.

[15] Yan, L. and Kim, I.H. Effect of Eugenol and Cinnamaldehyde on the Growth Performance, Nutrient Digestibility, Blood Characteristics, Fecal Microbial Shedding and Fecal Noxious Gas Content in Growing Pigs. Asian-Australasian J. Ani. Sci., 2012: 25(8), 1178 .

[16] Chen, Y.J., Min, B.J., Cho, J.H., Kwon, O.S., Son, K.S., Kim, H.J. and Kim, I.H. Effects of dietary Bacillus-based probiotic on growth performance, nutrients digestibility, blood characteristics and fecal noxious gas content in finishing pigs. Asian Australasian J. Ani. Sci., 2006; 19(4): 587

[17] Loh, T.C., Lee, T.M., Foo, H.L., Law, F.L. and Ajion, M.A. Growth performance and fecal microflora of rats offered metabolites from lactic acid bacteria. J. App. Anim. Res., 2008; 34(1): 61-64.

[18] Yan, L. and Kim, I.H. Effect of probiotics supplementation in diets with different nutrient densities on growth performance, nutrient digestibility, blood characteristics, faecal microbial population and faecal noxious gas content in growing pigs. J. Appl. Anim. Res., 2003; 41(1): 23-28.

[19] Yan, L. and Kim, I.H. Effect of probiotics supplementation in diets with different nutrient densities on growth performance, nutrient digestibility, blood characteristics, faecal microbial population and faecal noxious gas content in growing pigs. J. Appl. Anim. Res., 2003; 41(1), 23-28.

[20] Reid, G., Jass, J., Sebulsky, M.T. and McCormick, J.K. Potential uses of probiotics in clinical practice. Clinical Microbiology Reviews, 2003; 16(4); 658-672.
[21] Bernet, M.F., Brassart, D., Neeser, J.R. and Servin, A.L. Lactobacillus acidophilus LA 1 binds to cultured human intestinal cell lines and inhibits cell attachment and cell invasion by enterovirulent bacteria. Gut, 1994; 35(4): 483-489.

[22] Reid, G., Jass, J., Sebulsky, M.T. and McCormick, J.K. Potential uses of probiotics in clinical practice. Clinical Microbiology Reviews, 2003; 16(4); 658-672.

[23] Yolken, R.H., Ojeh, C., Khatri, I.A., Sajjan, U. and Forstner, J.F. Intestinal mucins inhibit rotavirus replication in an oligosaccharidedependent manner. J. Infect. Dis., 1994; 169(5): 1002-1006.

[24] Peter Cadieux, MSc; Jeremy Burton, PhD; Gillian Gardiner, PhD Ivo Braunstein; Andrew W. Bruce, MD; C. Yong Kang, Lactobacillus Strains and Vaginal Ecology, JAMA, 2002; 287(15).

[25] Probiotics in man and animals, R. FULLER AFRC Institute of Food Research, Reading Laboratory, Shinfield, Reading RG2 9AT, UK J. Appl. Bact., 1989; 66: 365-378.

[26] Czerucka, D., Piche, T. and Rampal, P. Review article: yeast as probiotics-Saccharomyces boulardii. Alimentary pharmacology and therapeutics, 2007; 26(6): 767-778.

[27] Aminov, R.I. and Mackie, R.I. Evolution and ecology of antibiotic resistance genes. FEMS Microbiology Letters, 2007; 271(2): 147 161.

[28] Choct, M., Managing gut health through nutrition. British Poultry Sci., 2009; 50(1): 9-15.

[29] Yousten, A.A., Johnson, J.L. and Salin, M.A.R.V.I.N. Oxygen metabolism of catalase-negative and catalase-positive strains of Lactobacillus plantarum. J. Bacter., 1975; 123(1): 242-247.

[30] Ashraf, R. and Shah, N.P. Antibiotic resistance of probiotic organisms and safety of probiotic dairy products. Int. Food Res. J., 2011; 18(3): 837-853.

[31] Kelly, B.G., Vespermann, A. and Bolton, D.J. Gene transfer events and their occurrence in selected environments. Food and Chem. Toxicol., 2009; 47(5): 978-983.

[32] Broadbent, J.R., Neeno-Eckwall, E.C., Stahl, B., Tandee, K., Cai, H., Morovic, W., Horvath, P., Heidenreich, J., Perna, N.T., Barrangou, R. and Steele, J.L. Analysis of the Lactobacillus casei supragenome and its influence in species evolution and lifestyle adaptation. BMC Genomics, 2012; 13(1): 533.

[33] http://www.optibacprobiotics.co.uk/blog/2014/07/can-probioticsprevent-antibiotic-resistance 